\title{
A Review of Targeted Therapies for Monogenic Epilepsy Syndromes
}

\author{
Vincent Zimmern ${ }^{1 *}$, Berge Minassian ${ }^{1}$ and Christian Korff ${ }^{2}$ \\ ${ }^{1}$ Division of Child Neurology, University of Texas Southwestern, Dallas, TX, United States, ${ }^{2}$ Pediatric Neurology Unit, \\ University Hospitals, Geneva, Switzerland
}

Genetic sequencing technologies have led to an increase in the identification and characterization of monogenic epilepsy syndromes. This increase has, in turn, generated strong interest in developing "precision therapies" based on the unique molecular genetics of a given monogenic epilepsy syndrome. These therapies include diets, vitamins, cell-signaling regulators, ion channel modulators, repurposed medications, molecular chaperones, and gene therapies. In this review, we evaluate these therapies from the perspective of their clinical validity and discuss the future of these therapies for individual syndromes.

Keywords: genetic epilepsy, gene therapy, anti-sense oligonucleotide, ketogenic diet, channelopathy, molecular chaperone

\section{OPEN ACCESS}

Edited by:

Mario Mastrangelo,

Umberto 1 Polyclinic, Italy

Reviewed by:

Bruria Ben-Zeev,

Sheba Medical Center, Israel

Gaetan Lesca,

Université Claude Bernard Lyon

1, France

*Correspondence:

Vincent Zimmern

vincent.zimmern@utsouthwestern.edu

Specialty section:

This article was submitted to

Pediatric Neurology,

a section of the journal

Frontiers in Neurology

Received: 04 December 2021

Accepted: 13 January 2022

Published: 17 February 2022

Citation:

Zimmern V, Minassian B and Korff C (2022) A Review of Targeted Therapies for Monogenic Epilepsy Syndromes.

Front. Neurol. 13:829116.

doi: 10.3389/fneur.2022.829116

\section{INTRODUCTION}

As of October 2021, the Online Mendelian Inheritance in Man database lists 1,285 genes or loci involved in epilepsy. Several of these discoveries have led to the development of gene-specific therapies-sometimes called "precision medicine"-ushering in a new era of gene-based therapies for epilepsy. By precision therapy or precision medicine, we mean any therapy that is either designed on the basis of the patient's underlying genetic diagnosis or which has been found through clinical trials to have a significant effect in a particular genetic epilepsy (even if the mechanism of the therapy is unknown). This broad definition of precision therapy is in contrast with an ad hoc treatment of seizures without any attention being paid to the genetic diagnosis.

In this review, we summarize the current state of precision therapies for monogenic epilepsy syndromes. These therapies are quite diverse, and include molecular chaperones, use or avoidance of ion channel blockade for channelopathies, repurposing of medications, diets, gene therapies including anti-sense oligonucleotides (ASO), RNA interference (RNAi), and inhibitors of overactive cellular signaling (1). While a genetic understanding of how individual patients metabolize and respond to anti-seizure medications are fast advancing (i.e., pharmacogenomics) and could be viewed as a personalized or precision therapy, these advances are outside the scope of this review (2). Throughout this review, we discuss monogenic epilepsy syndromes that are characterized by developmental and epileptic encephalopathies (DEE), according to the definition proposed by the ILAE (3).

We characterize the precision therapies by their documented efficacy as follows:

- established, based on randomized clinical trials having demonstrated their usefulness,

- potential, based on small or non-randomized clinical trials or case reports

- hypothetical, based on animal studies or in vitro data, but little-to-no clinical evidence available yet.

This review will summarize these approaches based on type (e.g., molecular chaperone, diet, gene therapy) rather than on documented success (i.e., established, potential, hypothetical), as this 
creates a more logical scheme for categorization. Therapies were identified through recent reviews and additional literature review for monogenic epilepsy syndromes $(1,4-6)$. We conclude with a discussion on the future of precision medicine in genetic epilepsies.

\section{THERAPIES FOR GENETIC EPILEPSIES}

\section{Diet and Vitamins}

Specialized diets like the ketogenic diet and the modified Atkins diet have become a well-established therapeutic modality for severe seizure syndromes. Thanks to advances in our understanding of certain genetic epilepsies with underlying enzymatic or metabolic disturbances, specific diets and vitamins are increasingly becoming part of the precision medicine armamentarium (see Table $\mathbf{1}$ ).

One of the best-known examples of genetic disease that responds to a specialized diet is GLUT1 deficiency syndrome (GLUT1-DS), a syndrome that often provokes global developmental delay, movement disorders, and epilepsy, associated with low glucose in the cerebrospinal fluid (CSF) or hypoglycorrhachia. The hypoglycorrhachia and associated symptoms are caused by variants in SLC2A1 which encodes the type 1 glucose transporter located in the blood-brain barrier (BBB) (7). Because the lack of CSF glucose explains the symptomatology, providing ketones to the CNS via the ketogenic diet provides an alternate energy source for neurons. The ketogenic diet leads to improvements not only in the seizure burden but also in the motor and cognitive symptoms in GLUT1-DS $(8,9)$.

The use of ketogenic diet for other genetic epilepsies has expanded beyond the well-known application for GLUT1-DS. Two brothers with newly-identified disease-causing variants in phosphatidyl inositol glycan A (PIGA) resulting in X-linked recessive multiple congenital anomalies-hypotonia-seizures syndrome (MCAHS2) who had poorly controlled seizures on multiple anti-seizure medications (ASMs) were able to achieve seizure freedom with the ketogenic diet (10). Discontinuation of the diet led to seizure recurrence. This case report was the first to note a prompt seizure response with initiation of ketogenic diet in PIGA-associated early-onset epileptic encephalopathy (10).

Supplementation of pyridoxine (vitamin B6) and pyridoxine derivatives is another very impactful dietary measure for specific genetic epilepsies. Pyridoxine-dependent epilepsy (PDE) is a neurometabolic disorder that presents in the neonatal period with intractable seizures that respond sometimes in dramatic fashion to pyridoxine but not to typical ASMs (7, 11). While this form of epilepsy was known as early as the 1950's, its genetic origins were only identified in 2006 when biallelic variants in $A L D H 7 A 1$, the gene encoding antiquitin, were found to be responsible for this neonatal epilepsy syndrome (7). Interestingly, antiquitin is a dehydrogenase involved in lysine catabolism that is primarily unrelated to $\mathrm{B} 6$ metabolism, but its deficiency results in the accumulation of metabolites inactivate pyridoxal 5'-phosphate (PLP), which is the active form of pyridoxine that is necessary for healthy neurotransmitter function (7). Pyridoxine administration overcomes the inactivation of PLP and then normalizes the metabolic abnormality that causes neonatal seizures.

In 2005, pyridoxal phosphate-dependent epilepsy was found to be caused by bi-allelic variants in the PNPO gene encoding the PLP oxidase (7). PNPO is involved in the last step of PLP synthesis (the active form of vitamin B6). Phenotypically, patients with $P N P O$ deficiency present with epileptic encephalopathy, microcephaly, and developmental delay and respond well to PLP supplementation (7). Classically, patients with PNPO deficiency present in infancy and their epilepsy does not respond to pyridoxine, but the phenotypic spectrum of $P N P O$ deficiency is expanding as there are documented cases of PNPO deficiency with delayed onset or response to pyridoxine (rather than PLP), suggesting that clinicians need to keep an eye open for atypical presentations of this epilepsy (12).

Several patients with vitamin-B6 responsive epilepsy but with genetic testing negative for disease-causing variants in $A L D H 7 A 1$ and $P N P O$ were found to have bi-allelic variants in the PLPBP gene that encodes the proline synthetase co-transcribed homolog (PROSC) which was later renamed as PLP homeostasis protein (PLPHP) (7). This protein binds to PLP and is thought to be important for mitochondrial metabolism. As genetic sequencing technologies become more common in clinical practice, the list of genetic causes of vitamin B6-responsive epilepsy is likely to continue to increase.

Cerebral folate deficiency, caused by mutations in several genes implicated in the folate cycle (notably FOLR-1 which encodes the cerebral folate receptor), manifests as developmental regression with ataxia, choreoathetoid movements, and myoclonic epilepsy starting around age 3 (13). CSF analysis shows low levels of 5-methyltetrahydrofolate (5-MTHF, $<5$ $\mathrm{nmol} / \mathrm{L}$ ) but normal serum levels of that metabolite (13). The condition responds very well to high-dose folinic acid, making it important to make the correct diagnosis. Other folate derivatives, like 5-methyltetrahydrofolate, have also been used with some success (14).

Lastly, a relatively new genetic epilepsy syndrome caused by an inborn error of metabolism for which dietary supplementation acts as a precision medicine has been reported recently. Researchers were able to identify four children across three families who presented to medical care for epileptic encephalopathy, global developmental delay, and anemia with anisopoikilocytosis (15). They were able to identify biallelic variants in $C A D$, a gene encoding a multifunctional enzyme involved in de novo pyrimidine biosynthesis, as the likely cause of this neurometabolic disorder (15). Two of the children had a worsening neurodegenerative course resulting in death at ages 4 and 5 respectively, but the remaining two children were treated with oral uridine supplementation (which allows recycling of pyrimidines) and showed significant developmental progress (15). The authors suggest that there may be an indication for adding $C A D$ to the list of genetic conditions on the newborn 
TABLE 1 | Diet and vitamins for monogenic epilepsy.

\begin{tabular}{|c|c|c|c|c|}
\hline Gene & Epilepsy syndrome & Suggested precision medicine & Therapeutic rationale & $\begin{array}{l}\text { Status as precision } \\
\text { medicine }\end{array}$ \\
\hline$A L D H 7 A 1$ & Vitamin B6-deficient epilepsy & Pyridoxine, lysine-restricted diet & Impairment of lysine breakdown & Established (11) \\
\hline$C A D$ & DEE & Uridine & Disruption of pyrimidine metabolism & Established (15) \\
\hline $\begin{array}{l}\text { Folate cycle genes: FOLR-1, } \\
\text { MTHFR, DHFR, PCFT }\end{array}$ & $\begin{array}{l}\text { Cerebral folate transporter deficiency } \\
\text { (ataxia and refractory myoclonic } \\
\text { epilepsy) }\end{array}$ & $\begin{array}{l}\text { Folinic acid, } \\
\text { 5-methyltetrahydrofolate }\end{array}$ & $\begin{array}{l}\text { Supplementation of active metabolite } \\
\text { missing in folate cycle }\end{array}$ & Established $(13,14)$ \\
\hline$P / G A^{\star}$ & $\begin{array}{l}\text { X-linked recessive multiple congenital } \\
\text { anomalies - hypotonia - seizures } \\
\text { syndrome (MCAHS2), epileptic } \\
\text { encephalopathy }\end{array}$ & Ketogenic diet & Unclear & Potential (10) \\
\hline PNPO & Vitamin B6 - deficient epilepsy & Pyridoxal-5-phosphate & Supplementation of deficiency & Established (12) \\
\hline PLPBP & Vitamin B6 - deficient epilepsy & $\begin{array}{l}\text { Pyridoxine, } \\
\text { pyridoxal-5-phosphate }\end{array}$ & Supplementation of deficiency & Established (92) \\
\hline SLC2A1 (GLUT1) & GLUT1 deficiency syndrome & Ketogenic diet & Alternate energy source & Established $(8,9)$ \\
\hline
\end{tabular}

*Indicates the current absence of a molecular or genetic rationale for this particular therapy.

TABLE 2 | Inhibitors of cellular signaling.

\begin{tabular}{|c|c|c|c|c|}
\hline Gene & Epilepsy syndrome & Suggested precision medicine & Therapeutic rationale & $\begin{array}{l}\text { Status as precision } \\
\text { medicine }\end{array}$ \\
\hline $\begin{array}{l}\text { GATOR1 complex } \\
\text { (DEPDC5, NPRL2, NPRL3) }\end{array}$ & $\begin{array}{l}\text { Familial focal epilepsy with } \\
\text { variable foci }\end{array}$ & mTOR inhibitors (everolimus) & Inactivation of mTOR pathway & Potential $(1,93)$ \\
\hline GNAQ & Sturge-Weber-related epilepsy & mTOR inhibitors (sirolimus) & Inactivation of mTOR pathway & Potential (27) \\
\hline PIKЗCA & Intractable epilepsy & PI3K inhibitors & Suppression of PI3K signaling & Potential (29) \\
\hline TSC1, TSC2 & $\begin{array}{l}\text { Tuberous sclerosis, focal cortical } \\
\text { dysplasia }\end{array}$ & $\begin{array}{l}\text { mTOR inhibitors (sirolimus, everolimus, } \\
\text { 1,3,5-triazine derivatives) }\end{array}$ & Inactivation of mTOR pathway & Established (19) \\
\hline
\end{tabular}

screening as early detection of the disease could significantly impact the course of the illness.

\section{Inhibiting Overactive Cellular Signaling}

Several genetic epilepsy syndromes are the result of mutations in genes that regulate cellular proliferation. Medications that inhibit cellular overgrowth are rational drug candidates for these conditions and were found to be quite effective as adjunctive treatments (see Table 2). TSC1/2 mutations, result in hyperactivity of mTOR complex 1 (mTORc1) with mTOR being a key regulator of cell growth and survival. The hyperactivity produces abnormal neuronal differentiation and migration. Up to $90 \%$ of patients with tuberous sclerosis from TSC1/2 mutations will develop epilepsy, with twothirds of cases being medication-resistant (16). Everolimus, an mTOR inhibitor originally approved for the treatment of renal angiomyolipomas and TSC-associated subependymal giant cell astrocytomas, was subsequently approved as adjunctive therapy for TSC-associated focal seizures in children greater than age 2 (16). The randomized, double-blind, placebo-controlled phase 3 EXIST-3 study supported the use of everolimus as an adjunct if seizures could not be controlled with two ASMs (17). There is ongoing work to determine whether the indication for this drug should be extended to children younger than age 2, as some studies suggest a benefit for the infant age group (18).

Much of the research effort for mTORopathies has focused on everolimus but other mTOR inhibitors, specifically rapamycin or sirolimus, have also been studied (19). A mouse model of TSC with Tsc1 conditional inactivation primarily in glia exhibits progressive epilepsy and premature death. Early administration of rapamycin in Tsc1-inactivated mice prevented the development of epilepsy and premature death compared to the untreated mice, while late administration suppressed seizures in mice that had already started having seizures and also prolonged survival (20). The efficacy noted in this animal model has also been documented in two pediatric case reports. The first reported on a 10 year-old girl who experienced a dramatic decrease in seizure frequency after 10 months of rapamycin therapy (21). The second case report documented significant improvement in seizure frequency in eight children with TSC during the 1st year but with worsening of seizure frequency in three of those patients (22). After discontinuation of rapamycin, three of five children experienced recurrence of seizures, suggesting an overall benefit at least for the 1st year (22).

In addition to case reports, two studies thus far have evaluated the role of sirolimus in TSC-related epilepsy. An open-label study of sirolimus in children with TSC-related epilepsy (23) found that sirolimus treatment led to a statistically 
TABLE 3 | Precision therapies for channelopathies.

\begin{tabular}{|c|c|c|c|c|}
\hline Gene & Epilepsy syndrome & Suggested precision medicine & Therapeutic rationale & Status as precision medicine \\
\hline KCNA2 & DEE & 4-aminopyridine & Reducing current amplitudes & Potential (43) \\
\hline KCNQ2 & DEE & $\begin{array}{l}\text { Sodium channel blockers, retigabine, } \\
\text { gabapentin }\end{array}$ & $\begin{array}{l}\text { Selective potassium channel Kv7 opener } \\
\text { (retigabine), potassium channel Kv7 } \\
\text { activator (gabapentin) }\end{array}$ & $\begin{array}{l}\text { - Sodium channel blockers } \\
\text { established (44) } \\
\text { - Retigabine - potential (47) } \\
\text { - Gabapentin - potential (48) }\end{array}$ \\
\hline KCNT1 & $\begin{array}{l}\text { Epilepsy of infancy with migrating } \\
\text { focal seizures, nocturnal frontal } \\
\text { lobe epilepsy }\end{array}$ & $\begin{array}{l}\text { - Quinidine } \\
\text { - ASO }\end{array}$ & $\begin{array}{l}\text { - Potassium channel blockade in GOF } \\
\text { variants } \\
\text { - Gene silencing }\end{array}$ & $\begin{array}{l}\text { - Quinidine - potential }(7,49) \\
\text { - ASO - potential }(86)\end{array}$ \\
\hline PRRT2 & $\begin{array}{l}\text { Benign familial infantile epilepsy, } \\
\text { paroxysmal kinesigenic } \\
\text { dyskinesia }\end{array}$ & Sodium channel blocker & Failure of neurotransmission & Potential $(64,65)$ \\
\hline SCN1A & Dravet syndrome & $\begin{array}{l}\text { - Avoid sodium channel blockers } \\
\text { - Stiripentol } \\
\text { - Fenfluramine } \\
\text { - Cannabidiol } \\
\text { - ASO }\end{array}$ & $\begin{array}{l}\text { Loss of function of } \mathrm{NaV} 1.1 \text { sodium } \\
\text { channels }\end{array}$ & $\begin{array}{l}\text { - Avoidance of sodium channel } \\
\text { blockers - established }(1,6) \\
\text { - Stiripentol - established }(35) \\
\text { - Fenfluramine - potential }(36) \\
\text { - Cannabidiol - established }(16,37) \\
\text { - ASO - hypothetical }(84)\end{array}$ \\
\hline SCN2A & $\begin{array}{l}\text { Ohtahara syndrome, early } \\
\text { encephalopathy }\end{array}$ & Sodium channel blockers & Gain of function of NaV1.2 channel & Potential (31) \\
\hline SCN8A & DEE & $\begin{array}{l}\text { - Sodium channel blockers } \\
\text { - ASO }\end{array}$ & & $\begin{array}{l}\text { - Sodium channel blockers - potential } \\
\text { (42) } \\
\text { - ASO - hypothetical (85) }\end{array}$ \\
\hline
\end{tabular}

insignificant $41 \%$ decrease in seizure frequency compared to the standard-of-care. This result is in contrast with a larger pediatric study of sirolimus in TSC-related epilepsy that found a statistically-significant $78 \%$ decrease in seizure frequency, $47 \%$ of whom went on to be seizure-free (24). Subgroup analysis of patients with drug-resistant seizures also confirmed a statistically significant improvement in seizure control (24). Sirolimus may therefore become an important alternate for patients unable to tolerate everolimus. There are no randomized trials comparing sirolimus to everolimus but a retrospective multicenter study of patients with TSC-related epilepsy suggests that there were more adverse events and dosing issues with sirolimus use compared to everolimus (25). There are also newer 1,3,5-triazine derivatives under development that have shown promise as mTORc1/2 inhibitors as they have excellent tolerability profiles and demonstrate marked suppression of spontaneous recurrent seizures in two mouse models of epilepsy, including a mouse model of TSC-related epilepsy (26).

Other disorders of cellular proliferation-including SturgeWeber syndrome caused by mutations in GNAQ, NPRL3related cortical malformations, and PIK3CA-related overgrowth syndromes-also present with epilepsy that seems responsive to "rapalogs" like sirolimus and everolimus. A retrospective observation study of six patients with refractory epilepsy from Sturge-Weber syndrome reported complete seizure control in all patients with minimal side-effects (27). A case report of a neonate with NPRL3-related epilepsy reported 3.5 months of seizure control that allowed the patient to grow seizure-free until epilepsy surgery (28). Mutations in the catalytic subunit of phosphoinositide 3-kinase (PIK3CA) are associated with a phenotypic spectrum of bilateral dysplastic megalencephaly and focal cortical dysplasia causing pediatric epilepsy. In a mouse model of PIK3CA-related epilepsy expressing the most common human mutations and which recapitulates the human phenotype, a new inhibitor of PI3K signaling that is being trialed for solid tumors (BKM120, a 2,6-dimorpholino pyrimidine derivative) significantly increased the seizure threshold (29). While these studies are promising, there is an ongoing need for studies of mTOR inhibitors for other mTOR-opathies involving mutations in related genes such as the GATOR complex (DEPDC5, NPRL2).

\section{Ion Channel Modulators}

Many genetic epilepsies stem from mutations in genes encoding voltage-gated ion channels and are generally referred to as "channelopathies." This section will discuss the use of ionchannel modulators for these genetic epilepsies, specifically sodium and potassium channelopathies (see Table 3). It should be noted that precision therapies other than ion-channel modulation have also been developed for these channelopathies and these are covered in their respective sections.

\section{Sodium Channelopathies}

In order of population prevalence, SCN1A, SCN2A, and $S C N 8 A$ are the four voltage-gated sodium channel genes that are most commonly associated with epilepsy (30-32). We will first consider therapies for SCN1A before addressing precision therapies for $S C N 2 A / 8 A$-related epilepsy because similar considerations regarding sodium channel blockade apply to these three conditions (7).

SCN1A mutations are associated with various forms of seizures and epilepsies on a wide spectrum of severity, including "isolated" febrile seizures as well as Dravet syndrome (DS), a 
developmental and epileptic encephalopathy of poor prognosis. Eighty percent of DS cases are associated with loss-of-function (LOF) mutations in SCN1A that encodes the voltage-gated sodium channel Nav1.1, particularly in inhibitory interneurons (33). Precision therapy for DS involves avoidance of sodium channel blockers (e.g., carbamazepine, lamotrigine), as they can worsen symptoms in some patients, as well as the use of agents that enhance GABAergic neurotransmission (e.g., clobazam) $(33,34)$. Typically, seizures remain refractory to multiple drug combinations, and no single therapeutic approach has shown long-term efficacy in these patients, up to now. Though not yet developed for clinical use, a peptide derived from spider venom (Hm1a) seems promising as it selectively activates the Nav1.1 channel with consequent improvement in seizure and mortality outcomes in a mouse model of DS (33). Other precision therapies for DS [i.e., stiripentol, fenfluramine, and cannabidiol (35-37)] will be discussed in the next section on repurposed medications.

Disease-causing variants in $S C N 2 / 8 \mathrm{~A}$ present in a very heterogenous manner that ranges broadly from developmental delay without epilepsy to severe early-onset DEE. Adding to this complexity, individuals with identical variants can present very differently $(31,32,38)$. Despite this diversity of clinical presentations, a pattern seems to be emerging which suggests that patients with gain of function (GOF) variants exhibit the more severe early-onset epileptic encephalopathies (EE) while patients with LOF variants present later in life with autism or developmental delay $(7,39-41)$. This general rule about GOF vs. LOF variants will certainly need further studies to establish its validity, but for the time being it provides clinicians with a rationale for the current management of these sodium channelopathies [e.g., the use of sodium channel blockers like high-dose phenytoin for patients with early-onset SCN8A epilepsy (42)]. When it comes to the sodium channelopathies as a whole, their clinical response to sodium channel blockers remains an important area of research.

\section{Potassium Channelopathies}

4-aminopyridine is a potassium channel blocker that can antagonize GOF defects in the KCNA2 gene that cause a DEE. In a study of $\mathrm{n}$-of- 1 trials in nine different centers, nine of 11 patients showed improvement in seizure burden, gait, ataxia, alertness, and cognition after starting 4-aminopyridine (43). Because of these findings, it seems a promising tailored treatment for KCNA2-encephalopathy caused by GOF variants.

Heterozygous variants (usually frameshifts or deletions) in KCNQ2, which encodes the alpha subunit of the potassium channel Kv7.2, underlie the majority of the autosomal dominant cases of benign familial neonatal epilepsy (BFNE). Variants in this gene associated with DEE are more commonly missense variants with a dominant negative effect (44). Most of these variants seem to induce loss of function of the voltage-gated potassium channel. Sodium channel blockers, which are not a form of precision medicine for this condition, have shown some efficacy, specifically for BFNE (45). Molecular insights into KCNQ2 disease-causing variants are stimulating research into targeted therapies. Ezogabine (EZO), for example, increases the opening of KCNQ2 channels, providing a rationale for its use in KCNQ2 variants that decrease potassium channel activity (44). In 11 patients treated with EZO, seizure reduction and improvements in development were noted in three out of four patients treated before 6 months, and two out of seven patients treated after that age (44). Much like EZO, retigabine and gabapentin have been shown in-vitro to be selective Kv7 openers and seem poised to be used for KCNQ2-related epilepsy $(46,47)$. For example, initiation of gabapentin led to rapid and sustained improvement in seizures in a patient with KCNQ2 DEE (48). Retigabine is an ASM that has been pulled from the market due to significant sideeffects but had shown significant promise for refractory epilepsy - there is cause for optimism as new retigabine analogs with fewer side-effects are under development (47).

Pathogenic variants in KCNT1, also encoding a potassium channel, are responsible for a broad phenotypic spectrum that include autosomal dominant nocturnal frontal lobe epilepsy (ADNFLE), early-onset epileptic encephalopathy (EOEE), and epilepsy of infancy with migrating focal seizures (EIMFS) in neonates and infants, which are often refractory to conventional ASMs (49). Initial studies suggested that KCNT1-related epilepsy caused by a GOF variant responds to quinidine, a sodium and potassium channel blocker mostly used as an anti-arrhythmic (50). However, subsequent clinical experience found that it was mostly ineffective in early-onset EE (51). A subsequent study of patients with KCNT1-related epilepsy noted a $>50 \%$ seizure reduction in $20 \%$ of patients, and with only a few achieving transient seizure freedom (49). While quinidine has had mixed results for this monogenic epilepsy syndrome, its robust efficacy in patients with specific variants in KCNT1 does give hope that it may become standard therapy for those specific variant (49). Till then, KCNT1 serves as an important reminder that, despite strong biomolecular evidence suggesting a certain therapy (e.g., ion channel modulation), the road to a successful therapy can sometimes be more complex than initially expected.

\section{Repurposing Established Medications}

As mentioned in the previous section, quinidine is an antiarrhythmic agent that is being put to novel therapeutic use in epilepsy, an example of a repurposed drug. In this section, we discuss additional repurposed medications as examples of targeted therapies for monogenic epilepsy (see Table 4).

\section{Dravet Syndrome}

We have previously discussed the avoidance of sodium channel blockade in DS. Fenfluramine (36), cannabidiol (37), and stiripentol (35) have all been found to provide clinical benefit for this severe epilepsy syndrome in randomized clinical trials (52). These clinical findings are buttressed by animal studies, including a study of fenfluramine and norfenfluramine in a zebrafish model of DS (53) and a study of cannabidiol and stiripentol in hyperthermia-induced seizures in a mouse model of DS (54). We include these medications as "precision therapies" given their efficacy, even though the precise mechanism of action in DS patients is not fully understood. Fenfluramine was initially marketed as an appetite suppressant, typically in combination with the monoamine oxidase inhibitor phentermine. It was pulled from the market in the 1980's due to concerns of valvular 
TABLE 4 | Repurposed medications for monogenic epilepsies.

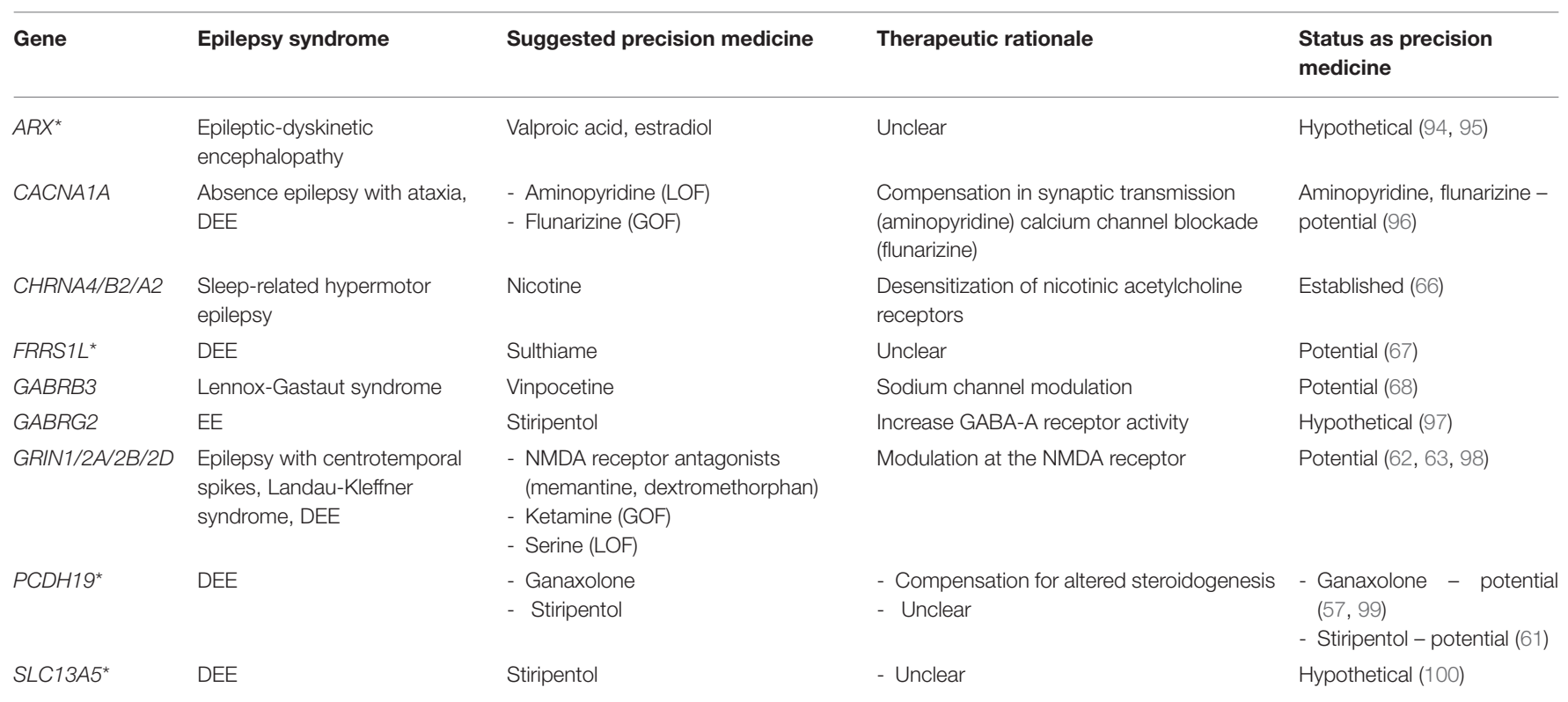

*Indicates the current absence of a molecular or genetic rationale for this particular therapy.

heart disease and pulmonary hypertension (16). However, subsequent studies have demonstrated its safety in DS patients (36, 55, 56). Regarding cannabidiol, there is a need for independent studies as the landmark study of this drug in DS was financed by GW pharmaceuticals (37).

\section{Protocadherin 19 Female Epilepsy}

Protocadherin 19 female epilepsy (PCDH19-FE) is an increasingly reported form of epilepsy whose pathophysiology is poorly understood. Disease-causing variants in PCDH19 lead to early-onset DEE with clustering epilepsy (CE) as well as altered steroidogenesis and nuclear-hormone-related gene expression changes. The known involvement of hormonal pathways in the pathogenesis of PCDH19-related epilepsy has prompted researchers to look for steroid-based treatments for this disorder. Results for corticosteroid therapy are mixed (57-59). Because patients with PCDH19-FE have been found to have lower levels of allopregnanolone, it has been theorized that replacement of that hormone with a synthetic analog, ganaxolone, which acts as a human neurosteroid, could be therapeutic (60). Stiripentol has also been found to be beneficial as an adjunctive ASM in PCDH19-FE, as documented in a case report of a young girl who became seizure-free for an unprecedented 2 years and 10 months after starting stiripentol as an add-on to valproate and clobazam (61).

\section{GRIN-Related Epilepsy}

Mutations in GRIN1/2A/2B/2D are associated with childhoodonset epilepsy and developmental delay. Depending on the resulting change in the protein structure of the N-methyl-Daspartate receptor (NMDAR), certain mutations cause increased charge transfer while other variants reduce current. Case reports have suggested a role for NMDAR blockade with dextromethorphan (typically used in cough syrup) or memantine (used for Alzheimer's dementia) for variants that cause gainof-function (62), while a single case report suggests L-serine supplementation for loss-of-function variants (63). It should be noted that functional changes of receptor function (e.g., NMDA and GABA) or ion channel function, as determined with in vitro techniques or in-silico approaches, may end up being more relevant for the development of therapies than the current GOF/LOF dichotomy.

\section{PRRT2-Related Epilepsy}

PRRT2-related epilepsy provides a good example of repurposing drugs that had already been proved effective for a movement disorder caused by the same gene. PRRT2 disease-causing variants are among the most common genetic causes of epilepsy. PRRT2 encodes a pre-synaptic transmembrane protein that enables synaptic vesicle fusion (7). Mutations in PRRT2 are associated with a broad clinical spectrum with three major phenotypes that include self-limited familial infantile seizures, paroxysmal kinesigenic dyskinesia (PKD), and infantile convulsions with choreoathetosis (64). Precision medicine therapy for PRRT2-related seizures with carbamazepine came from the common genetics shared between PKD and the infantile seizures. PKD had been treated effectively for years with carbamazepine and once it was understood that PRRT2 variants explained both PKD and familial infantile seizures, carbamazepine and oxcarbazepine were used effectively for PRRT2-related infantile seizures $(7,65)$.

\section{Miscellaneous Syndromes}

In the last chapter of this section, we discuss a few monogenic epilepsy syndromes for which there is limited evidence (e.g., case series or reports) for certain repurposed medications. 
TABLE 5 | Molecular chaperone treatments.

\begin{tabular}{|c|c|c|c|c|}
\hline Gene & Epilepsy syndrome & Suggested precision medicine & Therapeutic rationale & $\begin{array}{l}\text { Status as precision } \\
\text { medicine }\end{array}$ \\
\hline LG/1 & Familial temporal lobe epilepsy & $\begin{array}{l}\text { Phenylbutyrate, only for secretion-defective } \\
\text { mutations }\end{array}$ & Molecular chaperone & Hypothetical (71) \\
\hline STXBP1 & Ohtahara syndrome, West syndrome & $\begin{array}{l}\text { Phenylbutyrate in specific missense mutations } \\
\text { and possibly LOF mutations }\end{array}$ & Molecular chaperone & Hypothetical (70) \\
\hline
\end{tabular}

Autosomal dominant sleep-related hypermotor epilepsy caused by mutations in CHRNA4 (cholinergic receptor, nicotinic, and alpha polypeptide 4) responds strikingly well to transdermal nicotine patches in a pediatric case series (66). Hypermotor seizures disappeared entirely, but sporadic arousals persisted. Ferric chelate reductase 1 like (FRRS1L) encephalopathy is a rare cause of DEE with only a few cases reported worldwide and with mostly drug-refractory seizures. A case report of a Malaysian child with FRRS1L encephalopathy documented excellent seizure response to sulthiame, a central carbonic anhydrase inhibitor used widely in Europe and Asia but not commonly used in North America (67). A woman with Lennox-Gastaut syndrome (LGS) from a disease-causing variant in GABRB3 experienced a sustained, dose-dependent decrease in epileptiform activity on EEG after starting vinpocetine, a synthetic derivative of vincamine which is an alkaloid derived from the periwinkle plant. Its antiepileptic properties are likely from a combination of sodium channel modulation and GABA-A activity potentiationfuture studies will be needed to determine its efficacy and pharmacokinetics in epilepsy (68).

\section{Molecular Chaperones}

Neurologists are very familiar with disorders of protein folding and aggregation, such as Huntington's disease and Alzheimer's disease, but may not be aware that certain genetic causes of epilepsy are also conformational disorders. For these genetic epilepsies, chemical chaperones-small molecules that correct these folding and aggregating abnormalitiesrepresent an important avenue for precision medicine. These compounds work in a myriad of ways, including stabilization of misfolded proteins, reducing aggregation, preventing deleterious interactions with other proteins, and modifying the activity of endogenous chaperones to promote more efficient folding and translocation of proteins to the appropriate intracellular or extracellular destinations (69) (see Table 5). Recent examples of chemical chaperones for genetic epilepsies include studies of Munc18-1 related epilepsy and LGI1-related epilepsy, which we will discuss next.

Heterozygous de novo mutations in STXBP1, which encodes Munc18-1, result in a syndrome consisting of epilepsy, intellectual disability and movement disorders that carries a poor prognosis (70). A recent study in yeast, worm, and mouse neurons has shown that several disease-linked missense mutations in this gene lead to the disease phenotype through a dominant-negative effect whereby the mutant protein becomes destabilized and forms aggregates that then deplete the functional levels of wildtype Munc18-1 protein by co-aggregation (70). Use of chemical chaperones (4-phenylbutyrate, sorbitol, and trehalose) reversed the deficits caused by the mutations, both in-vitro and in-vivo in these animal models (70). Because this approach stabilizes the remaining wild-type Munc18-1 protein, the authors of the study predict that this strategy will also work for not only missense mutations but also non-sense and truncation mutations, suggesting a possible path forward for treating the multiple genetic causes of Munc18-1-related epilepsy (70).

Mutations in LGI1, which encodes a neuronally-secreted protein, cause autosomal dominant lateral temporal lobe epilepsy (ADLTE). Yokoi et al. classified 22 reported missense mutations in LGI1 as either leading to defects in protein secretion (secretion-defective) or allowing proper secretion (secretioncompetent), and then generated two mouse models of ADLTE encoding mutant proteins that were representative of the two groups (71). The secretion-defective mouse model expressed LGIE383A protein, which was found to be prematurely degraded by the endoplasmic-reticulum (ER) quality-control machinery. The secretion-competent mouse model expressed LGI1S473L protein, which dimerized abnormally and was defective in binding to ADAM22, one of its known receptors. These two mutations resulted in loss of function (LOF) through compromised intracellular trafficking or ligand activity of LGI1 to ADAM22. Use of 4 phenylbutyrate, a chemical chaperone, restored LGI1E383A's ability to fold and bind to ADAM22 and improved the seizure susceptibility of the LGI1E383A model mice but not the LGI1S473L mice. In addition to identifying LGI1-related epilepsy as a conformational disease, this study suggests a bright future for chemical chaperones as a precision therapy for certain monogenic epilepsies.

\section{Gene Therapies}

Gene therapy aims to alleviate disease by introducing genetic material into target cells to restore proper physiologic function (72). For monogenic epilepsy syndromes, gene therapies target neurons in the central nervous system (CNS), which requires either intrathecal delivery to bypass the $\mathrm{BBB}$ or systemic administration of the therapy that crosses the BBB to then reach the entire brain. Most gene therapies are packaged in adenoassociated viruses (AAV) that have tropism to the brain, typically AAV9 because of its BBB-permeable capsid. However, while being a prime delivery vector for gene therapies, viral capsid size leads to a limitation in terms of DNA cargo $(<4.7 \mathrm{kB})$. 
TABLE 6 | Gene therapies for monogenic epilepsies.

\begin{tabular}{|c|c|c|c|c|}
\hline Gene & Epilepsy syndrome & $\begin{array}{l}\text { Suggested precision } \\
\text { medicine }\end{array}$ & Therapeutic rationale & $\begin{array}{l}\text { Status as precision } \\
\text { medicine }\end{array}$ \\
\hline$C D K L 5$ & DEE & $\begin{array}{l}\text { - AAV-mediated gene therapy } \\
\text { - Fenfluramine } \\
\text { - GSK3B-HDAC dual inhibitor } \\
\text { - GABA receptor antagonist }\end{array}$ & $\begin{array}{l}\text { - Genetic repair } \\
\text { - Serotonin release (fenfluramine) } \\
\text { - Histone deacetylase activity (GSK3B) } \\
\text { - Decrease of excessive } \\
\text { GABAergic transmission }\end{array}$ & $\begin{array}{l}\text { Hypothetical } \\
(75,101-104)\end{array}$ \\
\hline CSTB & $\begin{array}{l}\text { Unverricht-Lundborg disease } \\
\text { (progressive myoclonic epilepsy) }\end{array}$ & ASO & Restore normal gene splicing pattern & Hypothetical (88) \\
\hline DNM1 & DEE & AAV-mediated microRNA & RNA interference & Hypothetical (89) \\
\hline GYS1 & Lafora disease & ASO & Downregulation of glycogen synthase & Hypothetical (87) \\
\hline KCNA1 & Temporal lobe epilepsy & CRISPRa & $\begin{array}{l}\text { CRISPRa-mediated upregulation of Kv1.1 } \\
\text { channels }\end{array}$ & Hypothetical (105) \\
\hline
\end{tabular}

In addition to multiple delivery methods, there are also multiple approaches to gene therapy that we could subdivide loosely into gene editing, gene supplementation, and gene expression modification. We will discuss each of these approaches and the associated monogenic epilepsies that have been tackled using each approach (see Table 6). The details of each gene therapy are beyond the scope of this review, and the reader is directed to excellent reviews on each therapy (73).

\section{Gene Editing}

Gene editing methodologies, the most prominent of which is the CRISPR/Cas9 gene editing system, allow for direct correction of a genetic defect. Briefly, CRISPR/Cas9 is a gene editing approach in which DNA sequences called CRISPRs (Clustered Regularly Interspaced Short Palindromic Repeats) allow the targeting and destruction of specific DNA targets by Cas (CRISPR-associated) proteins (74). CRISPR/Cas9 technology may be particularly important for genetic epilepsies since dominant heterozygous missense mutations or small insertion-deletions make up a large percentage of the known pathogenic variations. These variants make appealing targets for correction with CRISPR/Cas9 (74), but therapies have yet to emerge for clinical use.

\section{Gene Supplementation}

Gene supplementation usually involves the insertion of a supplemental transgene into a cell to make up for a LOF genetic defect, but does not correct the underlying defect per se. This approach has been trialed for cyclin-dependent kinase-like 5 (CDKL5) deficiency disorder, which is an X-linked dominant disorder caused by de novo mutations in CDKL5 leading to a DEE. A gene supplementation study involving AAV delivery of the human CDKL5 gene in CDKL5 knock-out mice demonstrated improved behavior and restoration of synaptic function in neurons (75). While the study was limited (e.g., incomplete recapitulation of the human phenotype including seizures, weak effect of treatment on some parameters), it serves as a proof-ofconcept for gene supplementation strategies for CDKL5-related epilepsy $(72,75)$.

Similar work has been done in animal models of tuberous sclerosis complex. The proteins hamartin and tuberin function within a complex to inhibit mammalian target of rapamycin (mTOR)-mediated cell growth and proliferation. Mutations in TSC1 or TSC2 (hamartin and tuberin, respectively) lead to tuberous sclerosis complex, a tumor suppressor syndrome characterized by overgrowth in multiple organs including the brain, resulting in intellectual disability, autism, and epilepsy. Several gene supplementation strategies have shown promise in mouse models of TSC. A mouse model of TSC with neuronspecific hamartin loss showed marked improvement in survival, weight, gain, and motor behavior after intracerebrovascular (ICV) injection of an AAV expressing tagged form of hamartin (76). Similar results were obtained with an IV. Follow up work by the same team showed that similar improvements in both phenotype and histology could be achieved through intravenous (IV) injection as opposed to ICV injection (77). Similar gene therapy efforts in a mouse model of TSC2, using AAV-mediated delivery of a "condensed" form of human tuberin, also showed significant increase in mean survival and reduction in histological evidence of brain pathology (78). These studies, taken as a whole, demonstrate the significant potential of AAV-mediated gene supplementation for TSC1 and TSC2.

Gene supplementation strategies have also been tested in various ion channelopathies that lead to epilepsy. As mentioned in a previous section, DS is mostly caused by LOF mutations in SCN1A, a gene that encodes the $\alpha$ subunit of the voltagegated sodium channel Nav1.1 (72). As a result, most gene therapy efforts for DS have centered on increasing Nav1.1 expression. These efforts have been stymied by at least two factors. The first is that the $S C N 1 A$ gene $(6 \mathrm{kB})$ exceeds the packaging limit of AAV vectors. The second is that the proclivity to seizure in this syndrome seems to be caused by an inhibitionexcitation imbalance from loss of SCN1A expression primarily in interneurons-restoration of healthy gene function would therefore have to specifically be targeted toward this specific cell population (79).

While the $\alpha$ subunit exceeds the packaging limit, the $\beta 1$ multifunctional sodium channel auxiliary subunit does not exceed the limit. Moreover, the $\beta 1$ subunit has been shown to increase ion flow through the $\alpha$ subunit and promotes the trafficking of $\alpha$ subunits from an intracellular pool to the cell 
surface. Overexpression of $N a V \beta 1$ should in theory improve the function of residual voltage-gated channels and thereby improve the DS phenotype. A murine study evaluated the effects of a bilateral ICV injection of an AAV vector coding for a truncated mouse promoter based on a GABAergic neuron expressing gene called Gad-1 and mouse NaVR1, with appropriate control mice (80). Treatment led to a partial rescue of the disease phenotype that was sexually divergent (80). The moderate efficacy of the treatment may have been due to the moderate specificity of the chosen promoter for GABAergic neurons-however, this study did provide a proof-of-principle for future treatments (72).

\section{Gene Expression Modification}

Gene expression modification seeks to increase or decrease the expression of a gene product, also known as activation and inhibition, respectively. There are various techniques that fall under this category including anti-sense oligonucleotides (ASO) (81), RNA interference (RNAi) (82), and dCas9-based CRISPRa/i (83).

\section{Anti-sense Oligonucleotides}

ASOs are short, single-stranded oligodeoxynucleotides, usually 8-50 nucleotides in length, which bind to a target mRNA via complementary base pairing. The base pairing then leads to endonuclease-mediated transcript knockdown and decreased expression of the associated deleterious protein (81). Firstgeneration ASOs were limited by rapid turnover (i.e., RNA degradation) and insufficient intracellular concentration to impact target genes. Modifications to their chemical backbones led to 2 nd and 3rd generation ASOs that, in addition to targeting mRNA, could also bind non-coding RNAs and toxic RNAs, leading to a much wider range of clinical uses. Their main limitation remains the need for intrathecal administration as they do not cross the BBB (81).

ASOs are being used in animal models of seizure disorders related to ion channelopathies. DS was discussed in a previous section and is predominantly caused by mutations in SCN1A. Expression of SCN1A is mediated by an anti-sense non-coding RNA (SCN1ANAT). Upregulation of the healthy SCN1A allele using oligonucleotide-based compounds (AntagoNATs) to target SCN1ANAT in a knock-in mouse model of DS and in a non-human primate led to significant improvements in seizure phenotype in the animals (84). AntagoNATs may therefore become a helpful treatment paradigm for DS, though will likely limited by the weekly intra-cerebral administration that is required (72).

GOF mutations in the SCN8A gene encoding Nav1.6 results in DEE (85). Reduction of the levels of Scn8a transcript to $25-50 \%$ of typical expression levels using an ASO resulted in delayed seizure onset and increased survival in mouse models of both SCN8A encephalopathy and DS (85). This success in animal models will pave the way for further studies of ASOs to decrease the pathological increase in transcript expression for GOF mutations in SCN8A and SCN2A. LOF mutations in SCN8A and SCN2A resulting in pathological decrease in transcript expression would benefit from a CRISPRa strategy, to be discussed in a subsequent section (72).

A similar ASO strategy has been developed for GOF variants in KCNT1 that lead to epilepsy of infancy with migrating focal seizures (EIMFS) (86). A single ICV injection of a Kcnt1 gapmer (i.e., short DNA strands flanked by strands of RNA mimics) ASO in a mouse model of KCNT1-epilepsy led to significant reduction in seizure frequency and increased overall survival compared to mice treated with a control (i.e., non-hybridizing) sequence (86). These results suggest a promising road ahead for ASO-based therapies in KCNT1-associated epilepsy.

Lafora disease is a fatal, genetic progressive myoclonic epilepsy from mutations in EPM2A and NHLRC1 resulting in abnormal branching patterns in a subgroup of glycogen molecules. These abnormal glycogen molecules then precipitate and accumulate as Lafora bodies that then generate a neuroinflammatory response and neurodegeneration. Glycogen synthase, encoded by the GYS1 gene, is the enzyme responsible for glycogen branch elongation. While mutations in GYS1 are not responsible for Lafora disease, down-regulation of glycogen synthase with an ASO could lead to decreased elongation of glycogen polymers, thereby decreasing the formation of Lafora bodies (87). ICV injection of an ASO targeting the mRNA of brain-expressed GYS1 in a murine model of Lafora disease led to inhibition of further accumulation of Lafora bodies in older mice that had already formed bodies and prevented Lafora body formation in young mice that had not yet formed any (87). The inhibition of Lafora body formation correlated strongly with improvements in neuroinflammatory markers, suggesting all-inall that this approach could prevent and stop the progression of this currently fatal form of epilepsy that strikes otherwise-healthy teenagers (87).

Mutations in the cystatin B gene (CSTB), which encodes an inhibitor of several lysosomal cathepsins, result in UnverrichtLundborg disease (ULD), a form of progressive myoclonic epilepsy with limited pharmacological treatments (88). ASObased therapies uniquely designed for particular CSTB mutations seem to be on the horizon. An ASO therapy for a newlyidentified splicing mutation causing ULD restored the normal splicing pattern in a dose-specific manner in cultured cells from the affected patient, providing proof-of-principle for mutationspecific anti-sense therapy in ULD and similar genetic epilepsies (88). It should be noted, however, that the most common mutation causing ULD is an unstable expansion of a dodecamer repeat in the promoter region, leading to down-regulation of CSTB mRNA levels (88), and the remaining mutations are missense, non-sense, frameshift, and splice-site.

Before moving to a discussion of other gene therapy strategies, it should be noted that, in addition to the challenge of intrathecal administrations of the gene product mentioned previously, another limitation of ASOs is the need for multiple administrations per year-in contrast with the one-time administration of gene supplementation strategies.

\section{RNA Interference}

RNA interference (RNAi) has also emerged as an important player in the modification of gene expression for therapeutic 
purposes. In most cases, RNAi is used to silence dominant toxic genes in an allele-specific way, meaning that the technology ideally silences the toxic allele while allowing healthy expression of the normal allele (82). Briefly, RNAi refers to a process whereby double-stranded RNA (dsRNA) is processed into smallinterfering RNAs (siRNAs) by the ribonuclease-III (RNase-III) enzyme called Dicer. Measuring about 21-23 nucleotides in length, siRNAs are dsRNA intermediates that then pair up with a protein complex called the RNA-induced silencing complex or RISC. As the siRNA duplex is unwound, one strand called the "guide strand" is incorporated into RISC while the other strand, called the "passenger strand," is selectively eliminated. The elimination (i.e., cleavage of the targeted transcript) is done by the "slicer" component of RISC called Argonaute-2 (Ago2). AAVmediated delivery and liposome-mediated delivery remain the most common forms of siRNA delivery but several other exciting approaches are being actively developed (82).

To date, there are no human studies of RNA interference for the treatment of epilepsy. However, animal studies show some promise. De novo mutations in dynamin-1 (DNM1) cause a severe DEE with both infantile spasms (IS) and LGS, that is highly resistant to current ASMs (89). Prior to the association of pathogenic human variants in DNM1 and severe epilepsy, a spontaneous missense mutation in the mouse ortholog, called "fitful," had already been associated with epilepsy, and fitful homozygotes exhibit a DEE-like phenotype with developmental delay and severe seizures (89). A DNM1-targeted microRNA delivered by self-complementary AAV9 into fitful homozygous mice led to a decrease in the seizure phenotype and improved cellular features on brain histology. As hopeful as this initial study is, more work is needed since causative mutations in DNM1 in humans are usually heterozygous dominant negative, in contrast with the homozygous mouse model in this study. But as was discussed previously, RNAi is a good approach to envisage when dealing with dominant negative alleles that need to be silenced while maintaining normal expression of the healthy allele.

\section{CRISPRi/a}

Another approach to gene activation and inhibition relies on nuclease-deficient (or catalytically dead or deficient) dCas9 protein, in conjunction with various effector domains such as transcriptional activators to activate (called CRISPRa) or transcriptional inhibitors to inhibit (called CRISPRi) gene expression (83). Briefly, this process involves conversion of Cas9 protein from a DNA "scissor" into a gene activator by disrupting its nuclease activity. This is done by introducing mutations into the evolutionarily-conserved nuclease domains (RuvC and $\mathrm{HNH}$ ) of Cas9 to make dCas9, essentially converting the protein into an RNA-guided DNA-binding protein. From there, dCas9

\section{REFERENCES}

1. Syrbe S. Prazisionsmedizin fur genetische Epilepsien - am Anfang des Weges? Zeitschirft fur Epileptol. (2021) 34:1617. doi: 10.1007/s10309-021-00409-0 can be fused with an effector (i.e., a transcriptional activator such as VP64 or VPR, or a transcriptional repressor such as the Kruppel-associated box domain of Kox1). The resulting dCas9-effector fusion, when paired with a target-specific single guide RNA (sgRNA) then operates as an artificial transcription factor to activate or inhibit gene expression.

CRISPRa/i approaches to monogenic epilepsy have only been attempted in animal models but appear promising. A CRISPRa approach in a mouse model of DS led to significant decrease in febrile seizures compared to the wildtype control mice, but did not completely suppress all seizure activity (90). A similar result was obtained by a different team using a CRISPRa methodology delivered via AAV (91). Both studies suggest that upregulation of Scnla in inhibitory neurons leads to phenotypic improvement, even after the juvenile murine stage, opening a path for future therapies along these lines $(90,91)$. On a more cautious note, and has been noted in other reviews, these Cas9-based treatments do require long-term expression of exogenous Cas9 proteins in neurons, potentially leading to off-target immunogenic effects (72).

\section{CONCLUSION}

As genetic causes of epilepsy continue to be discovered, it will be important for clinicians and researchers to leverage genetic and molecular insights to produce precision therapies for these patients. This review highlighted the many ways that monogenic epilepsies can be treated in a targeted manner based on pathophysiological insights. Areas of ongoing promising research include phenotype-treatment studies meant to delineate the specific roles of genetic variants and advances in gene therapies including RNAi, ASO, and CRISPRa/i. Another important area of investigation is discovering the degree to which seizure burden contributes to developmental delays in these syndromes that commonly present as DEE-i.e., does the reduction of seizure frequency lead to an improvement in the developmental aspects of the condition $(7,31,40)$ ? As personalized therapies improve, the answer to this question will hopefully emerge.

\section{AUTHOR CONTRIBUTIONS}

VZ wrote the article. CK and BM reviewed and corrected the article. All authors contributed to the article and approved the submitted version. of genetic epilepsies: from empirical treatment to precision medicine. Pharmacol Res. (2016) 107:426-9. doi: 10.1016/j.phrs.2016.04.006

3. Fisher RS, Cross JH, French JA, Higurashi N, Hirsch E, Jansen FE, et al. Operational classification of seizure types by the International League 
Against Epilepsy: position paper of the ILAE Commission for Classification and Terminology. Epilepsia. (2017) 58:522-30. doi: 10.1111/epi.13670

4. Poduri A. A channel for precision diagnosis and treatment in genetic epilepsy. Ann Neurol. (2014) 76:323-4. doi: 10.1002/ana.24243

5. Reif PS, Tsai M, Helbig I, Rosenow F, Sebastian P, Tsai M, et al. Expert review of neurotherapeutics precision medicine in genetic epilepsies : break of dawn? Expert Rev Neurother. (2017) 17:381-92. doi: 10.1080/14737175.2017.1253476

6. Kearney H, Byrne S, Cavalleri GL, Delanty N. Tackling epilepsy with highdefinition precision medicine: a review. J Am Med Assoc Neurol. (2019) 76:1109-16. doi: 10.1001/jamaneurol.2019.2384

7. Helbig I, Ellis CA. Personalized medicine in genetic epilepsies possibilities, challenges, and new frontiers. Neuropharmacology. (2020) 172:107970. doi: 10.1016/j.neuropharm.2020.107970

8. Klepper J, Akman C, Armeno M, Auvin S, Cervenka M, Cross HJ, et al. Glut1 Deficiency Syndrome (Glut1DS): state of the art in 2020 and recommendations of the international Glut1DS study group. Epilepsia Open. (2020) 5:354-65. doi: 10.1002/epi4.12414

9. Fujii $\mathrm{T}$, Ito $\mathrm{Y}$, Takahashi $\mathrm{S}$, Shimono $\mathrm{K}$, Natsume J, Yanagihara $\mathrm{K}$, et al. Outcome of ketogenic diets in GLUT1 deficiency syndrome in Japan: a nationwide survey. Brain Dev. (2016) 38:628-37. doi: 10.1016/j.braindev.2016.01.002

10. Joshi C, Kolbe DL, Mansilla MA, Mason S, Smith RJH, Campbell CA. Ketogenic diet - a novel treatment for early epileptic encephalopathy due to PIGA deficiency. Brain Dev. (2016) 38:848-51. doi: 10.1016/j.braindev.2016.04.004

11. Scharer G, Brocker C, Vasiliou V, Creadon-Swindell G, Gallagher RC, Spector $\mathrm{E}$, et al. The genotypic and phenotypic spectrum of pyridoxine-dependent epilepsy due to mutations in ALDH7A1. J Inherit Metab Dis. (2010) 33:57181. doi: 10.1007/s10545-010-9187-2

12. Mills PB, Camuzeaux SSM, Footitt EJ, Mills KA, Gissen P, Fisher L, et al. Epilepsy due to PNPO mutations: genotype, environment and treatment affect presentation and outcome. Brain. (2014) 137:135060. doi: 10.1093/brain/awu051

13. Delmelle F, Thöny B, Clapuyt P, Blau N, Nassogne MC. Neurological improvement following intravenous high-dose folinic acid for cerebral folate transporter deficiency caused by FOLR-1 mutation. Eur J Paediatr Neurol. (2016) 20:709-13. doi: 10.1016/j.ejpn.2016.05.021

14. Molero-Luis M, Serrano M, O'Callaghan MM, Sierra C, Pérez-Dueñas B, García-Cazorla A, et al. Clinical, etiological and therapeutic aspects of cerebral folate deficiency. Expert Rev Neurother. (2015) 15:793802. doi: $10.1586 / 14737175.2015 .1055322$

15. Koch J, Mayr JA, Alhaddad B, Rauscher C, Bierau J, Kovacs-Nagy R, et al. CAD mutations and uridine-responsive epileptic encephalopathy. Brain. (2017) 140:279-86. doi: 10.1093/brain/aww300

16. Johannessen Landmark C, Potschka H, Auvin S, Wilmshurst JM, Johannessen SI, Kasteleijn-Nolst Trenité D, et al. The role of new medical treatments for the management of developmental and epileptic encephalopathies: novel concepts and results. Epilepsia. (2021) 62:85773. doi: $10.1111 /$ epi. 16849

17. French JA, Lawson JA, Yapici Z, Ikeda H, Polster T, Nabbout R, et al. Adjunctive everolimus therapy for treatment-resistant focalonset seizures associated with tuberous sclerosis (EXIST-3): a phase 3, randomised, double-blind, placebo-controlled study. Lancet. (2016) 388:2153-63. doi: 10.1016/S0140-6736(16)31419-2

18. Curatolo P, Franz DN, Lawson JA, Yapici Z, Ikeda H, Polster T, et al. Sustained reduction in seizure frequency with adjunctive everolimus for treatment-refractory seizures associated with tuberous sclerosis complex (TSC) in children under 6 years of age: results from the phase 3 EXIST-3 extension phase. Eur J Paediatr Neurol. (2017) 21:e33. doi: 10.1016/j.ejpn.2017.04.799

19. Saffari A, Brösse I, Wiemer-Kruel A, Wilken B, Kreuzaler P, Hahn A, et al. Safety and efficacy of mTOR inhibitor treatment in patients with tuberous sclerosis complex under 2 years of age - a multicenter retrospective study. Orphanet J Rare Dis. (2019) 14:1-14. doi: 10.1186/s13023-019-1077-6

20. Zeng LH, Xu L, Gutmann DH, Wong M. Rapamycin prevents epilepsy in a mouse model of tuberous sclerosis complex. Ann Neurol. (2008) 63:44453. doi: 10.1002/ana.21331
21. Muncy J, Butler IJ, Koenig KM. Rapamycin reduces seizure frequency in tuberous sclerosis complex. J Child Neurol. (2009) 24:477. doi: $10.1177 / 0883073808324535$

22. Canpolat M, Gumus H, Kumandas S, Coskun A, Per H. The use of rapamycin in patients with tuberous sclerosis complex: long-term results. Epilepsy Behav. (2018) 88:357-64. doi: 10.1016/j.yebeh.2018.09.020

23. Overwater IE, Rietman AB, Bindels-de Heus K, Looman CWN, Rizopoulos D, Sibindi TM, et al. Sirolimus for epilepsy in children with tuberous sclerosis complex: a randomized controlled trial. Neurology. (2016) 87:3077. doi: 10.1212/WNL.0000000000003077

24. He W, Chen J, Wang YY, Zhang MN, Qian-Lu, Wang QH, et al. Sirolimus improves seizure control in pediatric patients with tuberous sclerosis: a prospective cohort study. Seizure. (2020) 79:20-6. doi: 10.1016/j.seizure.2020.03.018

25. Krueger DA, Capal JK, Curatolo P, Devinsky O, Ess K, Tzadok M, et al. Short-term safety of mTOR inhibitors in infants and very young children with tuberous sclerosis complex (TSC): multicentre clinical experience. Eur J Paediatr Neurol. (2018) 22:1066-73. doi: 10.1016/j.ejpn.2018.06.007

26. Theilmann W, Gericke B, Schidlitzki A, Muneeb Anjum SM, Borsdorf $\mathrm{S}$, Harries T, et al. Novel brain permeant mTORC1/2 inhibitors are as efficacious as rapamycin or everolimus in mouse models of acquired partial epilepsy and tuberous sclerosis complex. Neuropharmacology. (2020) 180:108297. doi: 10.1016/j.neuropharm.2020.108297

27. Sun B, Han T, Wang Y, Gao Q, Cui J, Shen W. Sirolimus as a potential treatment for sturge-weber syndrome. J Craniofac Surg. (2021) 32:25760. doi: 10.1097/SCS.0000000000007034

28. Vawter-Lee M, Franz DN, Fuller CE, Greiner HM. Clinical letter: a case report of targeted therapy with sirolimus for NPRL3 epilepsy. Seizure. (2019) 73:43-5. doi: 10.1016/j.seizure.2019.10.007

29. Roy A, Skibo J, Kalume F, Ni J, Rankin S, Lu Y, et al. Mouse models of human PIK3CA-related brain overgrowth have acutely treatable epilepsy. Elife. (2015) 4:1-25. doi: 10.7554/eLife.12703

30. Claes L, Del-favero J, Ceulemans B, Lagae L, Broeckhoven CV, Jonghe $\mathrm{PD}$. De novo mutations in the sodium-channel gene SCN1A cause severe myoclonic epilepsy of infancy. Am J Hum Genet. (2001) 68:132732. doi: $10.1086 / 320609$

31. Wolff M, Johannesen KM, Hedrich UBS, Masnada S, Rubboli G, Gardella E, et al. Genetic and phenotypic heterogeneity suggest therapeutic implications in SCN2A-related disorders. Brain. (2017) 140:1316-36. doi: 10.1093/brain/awx054

32. Zaman T, Helbig I, Babic Bozovic I, DeBrosse S, Christina Bergqvist A, Wallis $\mathrm{K}$, et al. Mutations in SCN3A cause early infantile epileptic encephalopathy. Ann Neurol. (2018) 83:703-17. doi: 10.1002/ana.25188

33. Richards KL, Milligan CJ, Richardson RJ, Jancovski N, Grunnet M, Jacobson LH, et al. Selective NaV11 activation rescues Dravet syndrome mice from seizures and premature death. Proc Natl Acad Sci USA. (2018) 115:E807785. doi: 10.1073/pnas.1804764115

34. Brigo F, Igwe SC, Bragazzi NL. Antiepileptic drugs for the treatment of infants with severe myoclonic epilepsy. Cochrane Database Syst Rev. (2017) 2017:CD010483. doi: 10.1002/14651858.CD010483.pub4

35. Chiron C. Stiripentol for the treatment of seizures associated with Dravet syndrome. Expert Rev Neurother. (2019) 19:30110. doi: 10.1080/14737175.2019.1593142

36. Specchio N, Pietrafusa N, Doccini V, Trivisano M, Darra F, Ragona F, et al. Efficacy and safety of Fenfluramine hydrochloride for the treatment of seizures in Dravet syndrome: a real-world study. Epilepsia. (2020) 61:240514. doi: 10.1111/epi.16690

37. Devinsky O, Cross JH, Laux L, Marsh E, Miller I, Nabbout R, et al. Trial of cannabidiol for drug-resistant seizures in the Dravet syndrome. $N$ Engl J Med. (2017) 376:2011-20. doi: 10.1056/NEJMoa1611618

38. Zaman T, Abou Tayoun A, Goldberg EM. A single-center SCN8Arelated epilepsy cohort: clinical, genetic, and physiologic characterization. Ann Clin Transl Neurol. (2019) 6:1445-55. doi: 10.1002/acn3. 50839

39. Larsen J, Carvill GL, Gardella E, Kluger G, Schmiedel G, Barisic $\mathrm{N}$, et al. The phenotypic spectrum of SCN8A encephalopathy. Neurology. (2015) 84:480-9. doi: 10.1212/WNL.00000000000 01211 
40. Gardella E, Marini C, Trivisano M, Fitzgerald MP, Alber M, Howell KB, et al. The phenotype of SCN8A developmental and epileptic encephalopathy. Neurology. (2018) 91:1112-24. doi: 10.1212/WNL.0000000000006199

41. Johannesen KM, Gardella E, Encinas AC, Lehesjoki AE, Linnankivi T, Petersen MB, et al. The spectrum of intermediate SCN8A-related epilepsy. Epilepsia. (2019) 60:830-44. doi: 10.1111/epi.14705

42. Boerma RS, Braun KP, Broek MPH, Lindhout D, Kempen MV, Boon M, et al. Remarkable phenytoin sensitivity in 4 children with SCN8A -related epilepsy: a molecular neuropharmacological approach. Neurotherapeutics. (2016) 13:192-7. doi: 10.1007/s13311-015-0372-8

43. Hedrich UBS, Lauxmann S, Wolff M, Synofzik M, Bast T, Binelli A, et al. 4-Aminopyridine is a promising treatment option for patients with gain-of-function KCNA2-encephalopathy. Sci Transl Med. (2021) 13:114. doi: $10.1126 /$ scitranslmed.aaz4957

44. Millichap JJ, Park KL, Tsuchida T, Ben-Zeev B, Carmant L, Flamini $\mathrm{R}$, et al. KCNQ2 encephalopathy: features, mutational hot spots, and ezogabine treatment of 11 patients. Neurol Genet. (2016) 2:96. doi: 10.1212/NXG.0000000000000096

45. Sands TT, Balestri M, Bellini G, Mulkey SB, Danhaive O, Bakken $\mathrm{EH}$, et al. Rapid and safe response to low-dose carbamazepine in neonatal epilepsy. Epilepsia. (2016) 57:2019-30. doi: 10.1111/epi. 13596

46. Manville RW, Abbott GW. Gabapentin is a potent activator of KCNQ3 and KCNQ5 potassium channels. Mol Pharmacol. (2018) 94:115563. doi: $10.1124 / \mathrm{mol} .118 .112953$

47. Shi S, Li J, Sun F, Chen Y, Pang C, Geng Y, et al. Molecular mechanisms and structural basis of retigabine analogues in regulating KCNQ2 channel. J Membr Biol. (2020) 253:167-81. doi: 10.1007/s00232-020-00113-6

48. Soldovieri MV, Freri E, Ambrosino P, Rivolta I, Mosca I, Binda A, et al. Gabapentin treatment in a patient with KCNQ2 developmental epileptic encephalopathy. Pharmacol Res. (2020) 160:105200. doi: 10.1016/j.phrs.2020.105200

49. Fitzgerald MP, Fiannacca M, Smith DM, Gertler TS, Gunning B, Syrbe S, et al. Treatment responsiveness in KCNT1 -related epilepsy. Neurotherapeutics. (2019) 16:848-57. doi: 10.1007/s13311-019-00739-y

50. Milligan CJ Li M, Gazina E V, Heron SE, Nair U, Trager C, Reid CA, et al. KCNT1 gain of function in 2 epilepsy phenotypes is reversed by quinidine. Ann Neurol. (2014) 75:581-90. doi: 10.1002/ana.24128

51. Chong PF, Nakamura R, Saitsu H, Matsumoto N, Kira R. Ineffective quinidine therapy in early onset epileptic encephalopathy with KCNT1 mutation. Ann Neurol. (2016) 79:502-3. doi: 10.1002/ana.24598

52. Sisodiya SM. Precision medicine and therapies of the future. Epilepsia. (2021) 62:S90-105. doi: 10.1111/epi.16539

53. Li J, Nelis M, Sourbron J, Copmans D, Lagae L, Cabooter D, et al. Efficacy of fenfluramine and norfenfluramine enantiomers and various antiepileptic drugs in a zebrafish model of Dravet syndrome. Neurochem Res. (2021) 46:2249-61. doi: 10.1007/s11064-021-03358-2

54. Cao D, Ohtani H, Ogiwara I, Ohtani S, Takahashi Y, Yamakawa K, et al. Efficacy of stiripentol in hyperthermiainduced seizures in a mouse model of Dravet syndrome. Epilepsia. (2012) 53:1140-5. doi: 10.1111/j.1528-1167.2012. 03497.x

55. Zhang L, Li W, Wang C. Efficacy and safety of fenfluramine in patients with Dravet syndrome : a meta-analysis. Acta Neurol Scand. (2021) 143:33948. doi: 10.1111/ane.13387

56. Lagae L, Sullivan J, Knupp K, Laux L, Polster T, Nikanorova M, et al. Fenfluramine hydrochloride for the treatment of seizures in Dravet syndrome : a randomised, double-blind, placebo-controlled trial. Lancet. (2019) 394:2243-54. doi: 10.1016/S0140-6736(19)32500-0

57. Higurashi N, Takahashi Y, Kashimada A, Sugawara Y, Sakuma $\mathrm{H}$, Tomonoh $\mathrm{Y}$, et al. Immediate suppression of seizure clusters by corticosteroids in PCDH19 female epilepsy. Seizure. (2015) 27:1-5. doi: 10.1016/j.seizure.2015.02.006

58. Higurashi N, Nakamura M, Sugai M, Ohfu M, Sakauchi M, Sugawara Y, et al. PCDH19 -related female-limited epilepsy: further details regarding early clinical features and therapeutic efficacy. Epilepsy Res. (2013) 106:1919. doi: 10.1016/j.eplepsyres.2013.04.005
59. Lotte J, Bast T, Borusiak P, Coppola A, Cross JH, Dimova P, et al. Effectiveness of antiepileptic therapy in patients with PCDH19 mutations. Seizure. (2016) 35:106-10. doi: 10.1016/j.seizure.2016.01.006

60. Nys RD, Kumar R, Gecz J. Protocadherin 19 clustering epilepsy and neurosteroids: opportunities for intervention. Int J Mol Sci. (2021) 22:189769. doi: $10.3390 /$ ijms 22189769

61. Trivisano M, Specchio N, Vigevano F. Extending the use of stiripentol to other epileptic syndromes: a case of PCDH19-related epilepsy. Eur J Paediatr Neurol. (2015) 19:248-50. doi: 10.1016/j.ejpn.2014.11.008

62. Pierson TM, Yuan H, Marsh ED, Fuentes-Fajardo K, Adams DR, Markello $\mathrm{T}$, et al. GRIN2A mutation and early-onset epileptic encephalopathy: personalized therapy with memantine. Ann Clin Transl Neurol. (2014) 1:190-8. doi: 10.1002/acn3.39

63. Soto D, Olivella M, Grau C, Armstrong J, Alcon C, Gasull X, et al. l-Serine dietary supplementation is associated with clinical improvement of lossof-function GRIN2B-related pediatric encephalopathy. Sci Signal. (2019) 12:eaaw0936. doi: 10.1126/scisignal.aaw0936

64. Döring JH, Saffari A, Bast T, Brockmann K, Ehrhardt L, Fazeli W, et al. The phenotypic spectrum of prrt2-associated paroxysmal neurologic disorders in childhood. Biomedicines. (2020) 8:1-14. doi: 10.3390/biomedicines8110456

65. Okumura A, Shimojima K, Kurahashi H, Numoto S, Shimada S, Ishii A, et al. PRRT2 mutations in Japanese patients with benign infantile epilepsy and paroxysmal kinesigenic dyskinesia. Seizure. (2019) 71:15. doi: 10.1016/j.seizure.2019.05.017

66. Lossius K, de Saint Martin A, Myren-Svelstad S, Bjørnvold M, Minken G, Seegmuller C, et al. Remarkable effect of transdermal nicotine in children with CHRNA4-related autosomal dominant sleep-related hypermotor epilepsy. Epilepsy Behav. (2020) 105:106944. doi: 10.1016/j.yebeh.2020.106944

67. Hadi DA, Mohamed AR, Rethanavelu K, Khoo TB. Clonic seizures, continuous spikes-and-waves during slow sleep, choreoathetosis and response to sulthiame in a child with FRRS1L encephalopathy. Brain Dev. (2021) 44:6-11. doi: 10.1016/j.braindev.2021.08.006

68. Billakota S, Andresen JM, Gay BC, Stewart GR, Fedorov NB, Gerlach AC, et al. Personalized medicine: vinpocetine to reverse effects of GABRB3 mutation. Epilepsia. (2019) 60:2459-65. doi: 10.1111/epi.16394

69. Zhao J-H, Liu H-L, Lin H-Y, Huang C-H, Fang H-W, Chen S-S, et al. Chemical chaperone and inhibitor discovery: potential treatments for protein conformational diseases. Perspect Medicin Chem. (2007) 1:PMC.S212. doi: 10.4137/PMC.S212

70. Guiberson NGL, Pineda A, Abramov D, Kharel P, Carnazza KE, Wragg RT, et al. Mechanism-based rescue of Munc18-1 dysfunction in varied encephalopathies by chemical chaperones. Nat Commun. (2018) 9:4. doi: 10.1038/s41467-018-06507-4

71. Yokoi N, Fukata Y, Kase D, Miyazaki T, Jaegle M, Ohkawa T, et al. Chemical corrector treatment ameliorates increased seizure susceptibility in a mouse model of familial epilepsy. Nat Med. (2015) 21:19-26. doi: 10.1038/nm.3759

72. Turner TJ, Zourray C, Schorge S, Lignani G. Recent advances in gene therapy for neurodevelopmental disorders with epilepsy. J Neurochem. (2021) 157:229-62. doi: 10.1111/jnc.15168

73. Doudna JA. The promise and challenge of therapeutic genome editing. Nature. (2020) 578:229-36. doi: 10.1038/s41586-020-1978-5

74. Goldberg E. Gene therapy in models of severe epilepsy due to sodium channelopathy. Epilepsy Curr. (2020) 20:2147. doi: $10.1177 / 1535759720930044$

75. Gao Y, Irvine EE, Eleftheriadou I, Naranjo CJ, Hearn-Yeates F, Bosch $\mathrm{L}$, et al. Gene replacement ameliorates deficits in mouse and human models of cyclin-dependent kinase-like 5 disorder. Brain. (2020) 143:81132. doi: 10.1093/brain/awaa028

76. Prabhakar S, Zhang X, Goto J, Han S, Lai C, Bronson R, et al. Survival benefit and phenotypic improvement by hamartin gene therapy in a tuberous sclerosis mouse brain model. Neurobiol Dis. (2015) 82:2231. doi: 10.1016/j.nbd.2015.04.018

77. Prabhakar S, Cheah PS, Zhang X, Zinter M, Gianatasio M, Hudry E, et al. Long-term therapeutic efficacy of intravenous AAV-mediated hamartin replacement in mouse model of tuberous sclerosis type 1. Mol Ther Methods Clin Dev. (2019) 15:18-26. doi: 10.1016/j.omtm.2019.08.003 
78. Cheah PS, Prabhakar S, Yellen D, Beauchamp RL, Zhang X, Kasamatsu S, et al. Gene therapy for tuberous sclerosis complex type 2 in a mouse model by delivery of AAV9 encoding a condensed form of tuberin. Sci Adv. (2021) 7:1-13. doi: 10.1126/sciadv.abb1703

79. Yu FH, Mantegazza M, Westenbroek RE, Robbins CA, Kalume F, Burton $\mathrm{KA}$, et al. Reduced sodium current in GABAergic interneurons in a mouse model of severe myoclonic epilepsy in infancy. Nat Neurosci. (2006) 9:11429. doi: 10.1038/nn1754

80. Nibori Y, Lee SJ, Minassian BA, Hampson DR. Sexually divergent mortality and partial phenotypic rescue after gene therapy in a mouse model of Dravet syndrome. Hum Gene Ther. (2020) 31:339-51. doi: 10.1089/hum.20 19.225

81. Rinaldi C, Wood MJA. Antisense oligonucleotides: the next frontier for treatment of neurological disorders. Nat Rev Neurol. (2018) 14:922. doi: 10.1038/nrneurol.2017.148

82. Rodriguez-Lebron E, Paulson HL. Allele-specific RNA interference for neurological disease. Gene Ther. (2006) 13:57681. doi: $10.1038 /$ sj.gt.3302702

83. La Russa MF, Qi LS. The New State of the art: Cas9 for gene activation and repression. Mol Cell Biol. (2015) 35:3800-9. doi: 10.1128/MCB.00512-15

84. Hsiao J, Yuan TY, Tsai MS, Lu CY, Lin YC, Lee ML, et al. Upregulation of haploinsufficient gene expression in the brain by targeting a long noncoding RNA improves seizure phenotype in a model of Dravet syndrome. EBioMedicine. (2016) 9:257-77. doi: 10.1016/j.ebiom.2016.05.011

85. Lenk GM, Jafar-Nejad P, Hill SF, Huffman LD, Smolen CE, Wagnon JL, et al. Scn8a antisense oligonucleotide is protective in mouse models of SCN8A encephalopathy and Dravet syndrome. Ann Neurol. (2020) 87:33946. doi: 10.1002/ana.25676

86. Kahlig K, Reddy K, Wittmann M. Antisense oligonucleotide therapy for KCNT1. bioRxiv. (2021) 2021:2621. doi: 10.1101/2020.11.12. 379164

87. Ahonen S, Nitschke S, Grossman TR, Kordasiewicz H, Wang P, Zhao X, et al. Gys1 antisense therapy rescues neuropathological bases of murine Lafora disease. Brain. (2021) 2021:1-9. doi: 10.1101/2021.02.11.430846

88. Matos L, Duarte AJ, Ribeiro D, Chaves J, Amaral O, Alves S. Correction of a splicing mutation affecting an Unverricht-Lundborg disease patient by antisense therapy. Genes. (2018) 9:1-9. doi: 10.3390/genes9090455

89. Aimiuwu OV, Fowler AM, Sah M, Teoh JJ, Kanber A, Pyne NK, et al. RNAi-based gene therapy rescues developmental and epileptic encephalopathy in a genetic mouse model. Mol Ther. (2020) 28:170616. doi: 10.1016/j.ymthe.2020.04.007

90. Colasante G, Lignani G, Brusco S, Di Berardino C, Carpenter J, Giannelli $S$, et al. dCas9-based Scnla gene activation restores inhibitory interneuron excitability and attenuates seizures in Dravet syndrome mice. Mol Ther. (2019) 28:235-53. doi: 10.1016/j.ymthe.2019.08.018

91. Yamagata T, Raveau M, Kobayashi K, Miyamoto H, Tatsukawa T, Ogiwara I, et al. CRISPR/dCas9-based Scn1a gene activation in inhibitory neurons ameliorates epileptic and behavioral phenotypes of Dravet syndrome model mice. Neurobiol Dis. (2020) 141:104954. doi: 10.1016/j.nbd.2020.104954

92. Darin N, Reid E, Prunetti L, Samuelsson L, Husain RA, Wilson M, et al. Mutations in PROSC disrupt cellular pyridoxal phosphate homeostasis and cause vitamin-B6-dependent epilepsy. Am J Hum Genet. (2016) 99:132537. doi: 10.1016/j.ajhg.2016.10.011

93. Scheffer IE, Heron SE, Regan BM, Mandelstam S, Crompton DE, Hodgson $\mathrm{BL}$, et al. Mutations in mammalian target of rapamycin regulator DEPDC5 cause focal epilepsy with brain malformations. Ann Neurol. (2014) 75:7827. doi: 10.1002/ana.24126

94. Kwong AKY, Chu VLY, Rodenburg RJT, Smeitink J, Fung CW. ARX-associated infantile epileptic-dyskinetic encephalopathy with responsiveness to valproate for controlling seizures and reduced activity of muscle mitochondrial complex IV. Brain Dev. (2019) 41:883-7. doi: 10.1016/j.braindev.2019.07.003
95. Loring KE, Mattiske T, Lee K, Zysk A, Jackson MR, Noebels JL, et al. Early $17 \beta$-estradiol treatment reduces seizures but not abnormal behaviour in mice with expanded polyalanine tracts in the Aristaless related homeobox gene (ARX). Neurobiol Dis. (2021) 153:105329. doi: 10.1016/j.nbd.2021.105329

96. Imbrici P, Liantonio A, Camerino GM, De Bellis M, Camerino C, Mele A, et al. Therapeutic approaches to genetic ion channelopathies and perspectives in drug discovery. Front Pharmacol. (2016) 7:128. doi: 10.3389/fphar.2016.00121

97. Warner TA, Smith NK, Kang JQ. The therapeutic effect of stiripentol in Gabrg2 +/Q390X mice associated with epileptic encephalopathy. Epilepsy Res. (2019) 154:8-12. doi: 10.1016/j.eplepsyres.2019.04.006

98. Salpietro V, Dixon CL, Guo H, Bello OD, Vandrovcova J, Efthymiou S, et al. AMPA receptor GluA2 subunit defects are a cause of neurodevelopmental disorders. Nat Commun. (2019) 10:10910. doi: 10.1038/s41467-019-10910-w

99. Pharmaceuticals M. Study of Adjunctive Ganaxolone Treatment in Female Children With Protocadherin 19 (PCDH19)-Related Epilepsy (Violet Study). (2019) Available online at: https://clinicaltrials.gov/ct2/show/NCT03865732 (accessed February 3, 2022).

100. Alhakeem A, Alshibani F, Tabarki B. Extending the use of stiripentol to SLC13A5-related epileptic encephalopathy. Brain Dev. (2018) 40:8279. doi: 10.1016/j.braindev.2018.05.020

101. Gennaccaro L, Fuchs C, Loi M, Roncacè V, Trazzi S, Ait-Bali Y, et al. A GABAB receptor antagonist rescues functional and structural impairments in the perirhinal cortex of a mouse model of CDKL5 deficiency disorder. Neurobiol Dis. (2021) 153:105304. doi: 10.1016/j.nbd.2021.10 5304

102. Devinsky O, King LT, Schwartz D, Conway E, Price D. Effect of fenfluramine on convulsive seizures in CDKL5 deficiency disorder. Epilepsia. (2021) 62:e98-102. doi: 10.1111/epi.16923

103. Loi M, Gennaccaro L, Fuchs C, Trazzi S, Medici G, Galvani G, et al. Treatment with a gsk-3 $\beta /$ hdac dual inhibitor restores neuronal survival and maturation in an in vitro and in vivo model of cdkl5 deficiency disorder. Int J Mol Sci. (2021) 22:115950. doi: 10.3390/ijms221 15950

104. Olson HE, Daniels CI, Haviland I, Swanson LC, Greene CA, Denny AMM, et al. Current neurologic treatment and emerging therapies in CDKL5 deficiency disorder. $J$ Neurodev Disord. (2021) 13:1-11. doi: 10.1186/s11689-021-0 9384-z

105. Colasante G, Qiu Y, Massimino L, Di Berardino C, Cornford JH, Snowball A, et al. In vivo CRISPRa decreases seizures and rescues cognitive deficits in a rodent model of epilepsy. Brain. (2020) 143:891905. doi: 10.1093/brain/awaa045

Conflict of Interest: The authors declare that the research was conducted in the absence of any commercial or financial relationships that could be construed as a potential conflict of interest.

Publisher's Note: All claims expressed in this article are solely those of the authors and do not necessarily represent those of their affiliated organizations, or those of the publisher, the editors and the reviewers. Any product that may be evaluated in this article, or claim that may be made by its manufacturer, is not guaranteed or endorsed by the publisher.

Copyright (c) 2022 Zimmern, Minassian and Korff. This is an open-access article distributed under the terms of the Creative Commons Attribution License (CC BY). The use, distribution or reproduction in other forums is permitted, provided the original author(s) and the copyright owner(s) are credited and that the original publication in this journal is cited, in accordance with accepted academic practice. No use, distribution or reproduction is permitted which does not comply with these terms. 